\title{
A Comparative Study on Objectives and Components of Writing Skill in National Curriculum of Iran and America (New Jersey) at High School
}

\author{
Elham Ghaderi Doust
}

Sanandaj, Kurdistan, Iran

Ghaderidoost.elham@gmail.com

\author{
Keywords: Writing Skill, National Language Curriculum, Objectives and Components of \\ Education, Upper Secondary School
}

\begin{abstract}
This study aims to provide an introductory of the codification of the objectives and components of teaching writing within the National Language curriculum in upper secondary in correlation with elementary and lower secondary curriculums. The method is a qualitative analysis of the contents. The data includes the Persian Language curriculum in Iranian upper secondary schools (version 2007) and American core curriculum for Language Arts (in New Jersey, 2004) collected through library study and note taking from Iran and foreign documents. In the present research, objectives and components of teaching writing within the curriculums in countries cited are analyzed and perused based on Autonomous and Ideological approaches to literacy; suggesting that objectives and components of American curriculum for teaching writing are formularized and influenced by Ideological approach, whereas Iranian writing curriculum possess properties of Autonomous Approach (consciously or unconsciously) and characteristics concerned with Ideological approach are marginal in Iran. After discussing features of curriculums in America (New Jersey), impressed by the Ideological approach to literacy, we proceed to bring forward the advantages and drawbacks of objectives and components of Iranian curriculum for teaching writing and some suggestions to improve are mentioned.
\end{abstract}

\section{INTRODUCTION}

Persian is the cornerstone of national identity. It develops unity and bonds between Iranian races, as well as it, as a treasure, links the past with the present and future. Hence, it requires Iranian students to methodically and scientifically recognize the features and systematic body of the language in order to boost the ability to write and create masterpieces.

To teach students how to use language in different levels of education, the curriculums underline four skills including listening, speaking, reading and writing via decoding the phonetic symbols (audio) and linear symbols (visual elements), as well as encoding and way of employing them [9]. Writing is the most complex skill in any language. Its levels originate from transcription, a simple encoding, and then amount to creative writing, the ultimate level. It expects the students to attain the ultimate level in writing.

Subsequent to planning and compilation of Persian books in the lower secondary course (in 2007), revision and modification of them (in summer 2008), the planning and compilation of Persian books council in the modern pedagogical system for upper secondary course formed. In addition to this council, the subordinate committees on texts, writing, grammar and dictation activated. Some experts, critics and selected teachers in cooperation with professors, authorities and experts in literature group designed a new curriculum. It led into setting out "Persian language and literature syllabus" in 9 chapters. The third chapter explains the objectives and educating the course; also, it puts up the objectives in 3 scopes; recognition, versatility, and sentimental domains. It holds forth that students majored in the course are able to utilize the grammar and phraseology for writing and dictation in Persian.

Persian language and literature books structurally contain 2 parts: the first part is" Persian language" dealing with grammar, spelling points, writing and composition, and the second part is related to "Persian literature" including eloquence, spelling, and old grammar rules. Persian language and 
literature books structures display that writing skill is slightly concerned. The contents are introduced without any schematization and they disharmonize with the previous curriculums. The level of mastery of writing skill is unobvious in the present curriculum. With a view to these issues, we study the objectives and education components in national language curriculum in American high schools. Gaining the highest ranks in literacy in International Competitions- the United States obtained $9^{\text {th }}$ grade in (such as Pirls, 2001) - and availability of its Language Curriculum has been one of the reasons to choose America's curriculum.

The present study seeks for a scientific support for a Persian syllabus in high schools and expands the teachers' and planners' views on the objectives and training components in national language syllabus ; consequently, the doers' and audience's tendency is to strengthen. They lead to provide planners with a fit scheme to utilize in subsequent curriculums. The study follows the following objectives:

1. To study the objectives and training components in national language writing syllabus in Iranian high schools;

2. To study the objectives and training components in national language writing syllabus in American high schools;

3. To offer several propositions on planning writing syllabus in conformity with previous courses;

4. To develop planners' and teachers' point views on language learning components and objectives

And To examine the hypothesis under question, these research questions were proposed:

1. What are the objectives and training components in national language writing syllabus in Iranian high schools?

2. What are objectives and training components in national language writing syllabus in American high schools?

3. What are the similarities and dissimilarities between the objectives and education components in national language writing syllabus in American and Iranian high schools?

4. What are the potential advantages and disadvantages of the objectives and training components in national language writing syllabus in American and Iranian high schools?

5. Regarding the experiences, what propositions and schemes can be introduced to improve writing skill in Persian syllabus?

\section{THE LITERATURE REVIEW}

"Study on objectives and components of language arts in upper secondary school curriculum" is a novel theme. Naturally, some articles with a similar topic, but at different school grade, about research keywords(curriculum, language arts, upper secondary), content analysis's on upper secondary Persian language and literature books and some comparative studies separately focused on curriculums and literacy (in Iran and overseas)have been done before. These matters were great boosts in presenting this article. Unfortunately, these studies due to aesthetic informing are unknown. It is hoped to pay our respect to some of them through mentioning their names and works; for example, in a study by [5] entitled "The Underlying Theoretical Approaches to describing Literacy based on the curriculums in Iran, Indonesia, Senegal, Singapore, England, Canada, and the United States have expressed that The key angle to planning curriculums by priority is description of literacy and then fixing the best method in educating literacy regarding the facilities of countries. Planning curriculums from literacy and specify the manner of conveying it to society members. "Comparative Analysis on National curriculums in Primary Education in Iran and U.S.A" IS studied in an article by [10] to deliberate national language curriculums at primary stage in Iran and four states of America: California, Arizona, Virginia and Wisconsin. Also, [11] in another research entitled "the study of philosophic, psychological and linguistic principles of Persian curriculum in elementary level" studies the philosophic, psychological and linguistic principles of Persian curriculum, perspectives, approaches and policies in Primary Persian Curriculum . [6] Has done a similar study entitled "comparative study of teaching creative writing 
(composition) in national curriculum of Iran, America \& England at the primary stage. The author of this study aims to present standard methods to enhance the Iranian students' composition ability based on the mentioned foreign countries' curriculum. [14] in "survey contents of Persian books $(1,2)$ of first course in High Schools based on planning and psychological doctrines from teachers' and students' standpoints in first course of high school in Tabriz ${ }^{1}$ deliberates teachers' and students' perception of contents of Persian books(1,2) in 1998-1999 and puts some suggestions and provisory guidelines . There is another one, "National Curriculum in Primary Education in Iran and England" by [18]. Finally, [17] in "presenting a guide schema in applying policies in planning curriculum systems in modern high school course" reports that specifying, consciously incorporating and applying fit curriculums are grounded on theatrically, philosophically, culturally, socially and values-based exploring cornerstones of pedagogical department is the essential process of planning curriculums impressing other processes (formalizing and paleography of curriculums). The planning of curriculums would greatly be a partial process without "conceptualizing" this main phase and structuring it. Similar research dealt with this subject in other countries includes the one by [19] entitled "An English Language Arts Curriculum Framework for American Public Schools". In This curriculum framework, she provides standards designed to guide reading and English teachers in the development of a coherent English language arts curriculum from Pre-K to 12 . It is based on two premises: that learning in the English language arts should be cumulative and that the reading of increasingly challenging literary and non-literary works as well as the writing of increasingly extensive research papers are the basis for developing the independent thinking needed for self-government. "Media Literacy and English Language arts" by [12] and "All unilateralism of content in language arts" written by [8] are other samples in this field. The second article points to analyzing the digital forms of multifold literacy, manipulating and modifying them to provide English learners with a new insight and the author writes all students require experiencing opulent and well-fixed Language Arts Curriculums. Last but not least, in " A curriculum study of giftedstudent learning in the language arts " the author admits that language art curriculum for high ability learners must enjoy constant and secure measures and be formed according to their necessities in comprehension( by questioning and responding) [13].

\section{THEORETICAL FRAMEWORK OF THE RESEARCH}

The research manner, respecting the aim, is applicable-fundamental and is a case examination.

The study attempts to study samples of the objectives and education components in National Language writing syllabus in Iranian high schools. Then, it conducted a survey on curriculums in Iran and America in both libraries and internet contexts.

The evolution modality of education is a great challenge in countries worldwide since the sense of literacy varied. Literacy is the basis of perception and thought. As Hirsch defined, literacy is a common body of required capacities to make relations with others exhibited through conversation, reading, writing, mathematics, using media and various technologies. Literacy aims at promoting daily life, collaborative participation, eliminating human problems, as well as outspreading individually and social capacities of people and their society. Clearly, reaching the developmental goals requires educating citizens possessing sufficient literacy.

Generally, definitions of literacy come into two different frames; Ideological and Autonomous [5].The theory that ideological perspective on literacy follows the culture of society is expressed by $[20,21$, and 22]. Within this theory, literacy is a social activity rather than a technical and global (universal) skill. It does not refer to unique but multidimensional phenomena and individuals acquire various levels of literacy by diverse techniques [16].

One of the genres of ideological literacy is the "critic literacy". As an educational approach, it asserts the critical views on texts. It offers some strategies to understand the messages of texts and encourage readers to actively analyze texts. Another genre is applicable (functional) literacy. The latter refers to develop a tight correspondence between literacy and particular circumstances and

\footnotetext{
${ }^{1}$ A city located in the West part of Iran
} 
contexts [2]. The third genre of ideological literacy is medium literacy. Over the past 5 decades, medium literacy became an equivalent for the potency for qualified analyzing and artful acquisition of printed media, cinema products, radio and TV programs and even computer data,(such as online intercommunication via The Internet).

Autonomous literacy is a unique and one-dimensional technical proficiency. In this frame, literacy focuses on learning lingual skills and indicates the ability to read and write. To be literate means having the ability to use the written texts ,materials and the technical proficiency on encoding and decoding as well (regardless of communicating) [15]. Based on this perspective literacy would not have any orientation and may be used for any purpose (whether bad or good, personal or collective).in this attitude it is a bound set of skills and emphasizes on acquiring knowledge.

A type of Autonomous literacy is "fundamental literacy "which refers to the ability to read and write, but a question arises: which level of literacy is sufficient? [3]. In interpreting literacy as an ability to read and write, there are not the required levels of skills in these realms. Another type of Autonomous nature is literacy of "human assets" [1]. The theory refers to the skill of promoting workers to major human fund. The prompt upheaval in technologies and virtual communications and universalities eventuate in striking innovation in workplaces. As in industrial revolution, work in factories supplanted work in fields, in such a space, professions altered from resources-based to science-based in computers and IT. In the industrial revolution, farmers were qualified to accept a new profession in manufactories, while they presently lack any acquirement and craft to enter the professional and electronic businesses [7]. In the midst of the eighth decade, changes in the industry made the workers with high fringe benefit unemployed because it was insoluble to re-educate them. As set forth in the introductory, the focus is on studying and analyzing the objectives and training components in national language writing syllabus in American and Iranian high schools to recognize whether teaching the lingual skills is independent of social-cultural context or dependent on the context(Ideological). The present study also aims at discussing the underlying theoretic approach to teaching writing skill and its advantages and drawbacks through analyzing the objectives and training components in national language writing syllabus in Iranian curriculum. The argument is simplified by the following table on these approaches.

Table 1. Characteristics of Ideological and Autonomous approaches to literacy

\begin{tabular}{|c|c|c|}
\hline & characteristics of the Ideological approach & characteristics of Autonomous approach to literacy \\
\hline 1 & $\begin{array}{l}\text { Focuses on encoding and decoding of texts rather } \\
\text { than communications }\end{array}$ & Focuses on communications \\
\hline 2 & $\begin{array}{l}\text { Recognizes literacy as a professional and global } \\
\text { skill (without any orientation and regarding the } \\
\text { social context). It equates it in all contexts in any } \\
\text { society }\end{array}$ & $\begin{array}{l}\text { Recognizes literacy as a context-based skill. It } \\
\text { differentiates literacy among various cultures and } \\
\text { societies. }\end{array}$ \\
\hline 3 & Does not concentrate upon critical literacy & concentrates upon critical literacy \\
\hline 4 & Just emphasizes on schooling & Is concerned with the potential of knowledge output \\
\hline 5 & $\begin{array}{l}\text { Does not emphasizes on Learning via different } \\
\text { technologies }\end{array}$ & Emphasizes on learning via different technologies \\
\hline 6 & $\begin{array}{l}\text { accounts literacy as a linear, one-dimensional and } \\
\text { particular matter }\end{array}$ & $\begin{array}{l}\text { Centers multimedia literacy(written, electronic, } \\
\text { speech) as well as multidimensional literacy }\end{array}$ \\
\hline 7 & Deals with learning skills & Deals with social activities \\
\hline 8 & accounts literacy as a set of limited skills & accounts literacy as an unsteady set of activities \\
\hline 9 & $\begin{array}{l}\text { Emphasizes on differences between literates and } \\
\text { illiterates }\end{array}$ & $\begin{array}{l}\text { Does not emphasizes on differences between literates } \\
\text { and illiterates }\end{array}$ \\
\hline 10 & $\begin{array}{l}\text { accounts literacy as an input-based matter so } \\
\text { focuses on education inputs and time assigned for } \\
\text { education }\end{array}$ & $\begin{array}{l}\text { accounts literacy as an output-based matter and } \\
\text { focuses on education efficiency }\end{array}$ \\
\hline 11 & Is not interested in regular assessments & $\begin{array}{l}\text { Is interested in regular assessments to avoid mistakes } \\
\text { and by rote learning }\end{array}$ \\
\hline
\end{tabular}




\section{DISCUSSION AND RESULTS}

\section{Specifying the objectives and elements in educating language arts in National Curriculum in Upper Secondary schools; New Jersey (2004)}

New Jersey curriculums have been formalized as a document, named a joint curriculum. It includes a preface and content standards for 9 subjects including dramatic and visual arts, generic hygiene, physical education, language arts literacy, math, science, social studies, world languages, technology literacy, and professional education, living, family, and customer skills. In National language curriculum in this state, as a part of the joint curriculum, content standards for language arts education (reading, writing, listening, speaking, observation and media literacy) from Kindergarten to twelfth grade have been expounded. They include linguistic experiences challenging students to socially, intellectually, and sensationally develop. The purpose to determine such standards is to promote students' abilities in accessing to the significance of all subjects. If students learn to read, write, speak and listen and critically, strategically, and creatively observe and employ them for themselves individually and collectively, they may enjoy the necessary literacy skills for discovering meanings and purposes in their lifetimes. It should be stated that standards for $9^{\text {th }}-12^{\text {th }}$ grades revised and modified in January 2008.

The study explains the objectives and elements regarding writing skill and points to the targets in educating this skill. Then the characteristics of this skill are argued. The objectives and elements in content standards framework discussed in details are introduced into National Language Curriculum for $9^{\text {th }}-12^{\text {th }}$ grades. Education content standards in writing skill in this course would be explained as follows.

\section{Writing}

\section{A) Writing as a process (pre-writing, drafting, and revising, editing, post-writing):}

Full-writing by routine and sufficiently writing; using graphic organizers and headlines in writing drafts regarding the desired message, audience and target; analyzing and revising texts to adjust the structure, style, coordination in subjects, valid selection of words, diversity in sentences, and semantic accuracy; reviewing and technically editing texts to give fluidity and clarity; utilizing computers and word processors to write, revise, edit, and print the compositions; employing the measures to estimate writings by oneself and others all are parts of writing process.

\section{B) Writing as a product:}

This step includes studying features, tone, structure, and various linguistic particulars and applying them in writing; criticizing masterpieces to check their authenticity and accuracy; writing an assertion and cover it by exact concepts and ideas; writing several paragraphs during the curriculum through plot developing techniques (cause/effect, problem/solution, hypothesis/results, rhetorical questions, parallelism ${ }^{1}$,etc.); writing some essays and articles(persuasive, analytic, critic ,etc.); writing literary scholarship by applying the previous research and technology to support texts; utilizing the primary and secondary sources to forgather themes, justifications, as well as introducing sources like interviews, electronic media and discussion; provoking readers' interests by tools and fashions as precise language, citing special details, definitions, descriptions, illustrations, fables, allegories, and epigrams; writing absorbing introductions and convincing and argumentative conclusions; employing corresponsive figures to reinforce the main ideas (charts, diagrams, tables, pictures, computer presentations ,etc.); benefitting from others' opinions to review the contents, organize and utilize literary pieces; picking literary genres to offer.

\section{C) Technique of writing, dictation, and handwriting}

Following the principles and rules of Standard English throughout the writing (sentence structure, grammar and usages, punctuation, capitalization of first letters and spelling, etc.), using syntax to effectively convey the someone opinion; using the subordination, coordination, apposition and other tools to indicate coherence; using transition words to corroborate logical expressions; avoiding

\footnotetext{
${ }^{1}$ It refers to using equal structures after conjunctions
} 
redundancy, elision, repetition, contradiction to fortify the text; following the principles and rules of Standard English to edit someone and others' texts; using several sources (dictionaries, grammar books, software and Internet) to edit texts are the essential techniques.

\section{D) Forms of writing, audience and targets:}

Employing the most effective writing structures and strategic methods according to target and audience; mastery on writing genres like persuasive writing, personal descriptions, investigative reports, literary research, descriptive articles, critic, satire, poetry and special descriptive styles (myth, fable, novelette); checking action of the tone, word selection, style, content, author's viewpoint and figures of speech on writing; enjoying copyrights; using such structures as chronology, cause- effect relations, transition words, headings and subtitles in writing; gathering and utilizing information in daily life and workplace (job application, resume, commercial correspondence and enrolling university); expressing viewpoints and using personal style conforming with purposes and to affect readers are the most important elements regarding the forms of writing, audience and target.

\section{Analysis of writing skill in New Jersey Curriculum for high schools}

In educating writing skill process in this state, the students may learn to write precisely, transparently, and orderly so that the content and form of writing would be different according to its audience and purpose of writing. It suggests it is important to emphasize context and audience in teaching how to write. Writing is a complex process setting about one's thoughts. This skill is used for writing essays, communications, and expressions, learning and involving readers showing the significance of communicating with the audience- the reader- and creating a masterpiece. In writing assertions and their defending using ideas, authentic concepts and plot developing techniques as well as writing several persuasive, analytic, critic articles and essays, students attempt to generate a novel science. The study may stick to the value of exchanging information with readers. They provoke readers' interests through tools and fashions as citing special details, fables, allegories as well as by writing absorbing introductions and convincing and argumentative conclusions and strengthen their relations with their texts. Furthermore, students may realize opportunities to exercise writing, present ideas, revise, assess and publish their writings. They master eloquently writing over the process of writing including pre-writing, preparing, drafting, reviewing, editing drafts phases and post- writing phases as-publishing, introducing, evaluating ,and implementing; meanwhile, it is necessary to do some self-evaluating to assess and develop each other's writing. Bearing this in mind, it can be concluded that reviewing and evaluating fashions will be practical in teaching writing.

All students might learn to analyze and revise texts in order to modify style, structure, and choose perfect words. They may concentrate more on their writings and characterize certain targets and check their tone, structure, and linguistic properties to develop and expand their ideas. Also, they are taught to criticize masterpieces to evaluate their accuracy. They use other perspectives to organize and peruse them. Finally, they study the impression of tone, word choice, style, content, author's viewpoint and figures of speech. They discuss their daily and job necessities while they concentrate on the said information. Genres and their properties are taught overwriting. To clarify, in New Jersey, critical writing is instructed and there is a great emphasis on using technology and IT. Students are capable of revising and publishing texts by word processor software. They employ these experiences to write literary texts.

Toward the findings and table on the coordination of Ideological and Autonomous approaches to literacy, one might conclude that in New Jersey Curriculum for National Language in high schools, educating writing skill is scheduled according to the Ideological approach to literacy.

The objectives and components of Language Arts in National Language Curriculum in Iranian High Schools (1997; revised, 2008)

High School Persian Language and literature curriculum is framed as an experimental one and in 6 parts. "The need to plan a curriculum" is posed in the first part and advantages of new curriculum 
and planning phases are introduced. In this part to create a consensus among planners' council and audience as well as executors, certain words and terms are defined. Also planning approach to language and literature curriculums, teaching the Persian Language, teaching literature, emerging teaching methods with assessment systems are discussed in "approaches" formats. The second part refers to "targets" explaining final goals and learning objectives. In this part, objectives are categorized in two extents- language and literature- and three aspects- cognitive, proficiency, and sentimental. The third part proceeds to introduce the "content" and observes the curriculum planning principles to discuss the details and headings in two extents. "Methods and learningteaching methodologies are studied in the fourth section."Assessment" in two levels (macrocurriculum; minute- classroom) is pointed. At last, teachers' professional qualifications are mentioned.

Cognitive scope- knowledge- is one of the related scopes to language and literature objectives. According to [4] classification, this scope consists of six phases- knowledge, understanding, employing, analyzing, merging, and evaluating. The second scope, sentimental (perspective), comes into certain sections as receiving (considering), responding, and valuation, values organizing, and manifesting values through students' conducts. The final scope called as psyche-dynamic (proficiency) contains general body movements, delicate and coordinated movements, non-lingual, and lingual gestures.

\section{Analysis of writing skill in Iran Curriculum for High Schools}

Iranian National Language Curriculum observes some objectives, showing more emphasis on writing rather than reading. Unfortunately, the listening and speaking skills have been overleapt in this curriculum. There is an ambiguity in this curriculum. That is a level of literacy attained by students in these skills is not specified. However, the affirmative point is that educating students in three scopes will occur equivalently despite all disorganizations. Albeit, objectives, and components of teaching language arts are introduced separately and in psyche-dynamic scope, although, they are taught simultaneously.

In Persian Language Curriculum Framework for High Schools, students are rhetorically educated about Standard Persian and its impress on daily life and social intercourse, but they might receive no application to enjoy them. It seems true about grammar, syntax, and conjugation rules. Students are not taught to employ them to communicate with others. On the other hand, one of the objectives of the curriculum is to teach reflection and judgment fashions. This objective is generally mentioned and the subject to be judged is not marked. In the present curriculum, the students are informed that they should be capable of analyzing and judging, but the nature and manner of judgment are unknown in the curriculum. It makes us deduce that students do merely acquire and expand knowledge in educating Persian, respective to the cognitive theme. In this curriculum there is a great emphasis on didactic instruction rather than applying the knowledge in a social context; moreover, this curriculum deals with encoding and decoding. One who can read and write is assumed a literate person. It is important to distinguish between literate and illiterate people.

According to sentimental scope, possessing constructive attitude toward Persian Language and its usages in various tendencies is important. Also, students may familiarize with language arts applications in social activities and communicate with others and employ the knowledge in real life and collective activities to attend. This suggests the significance of communication while it just is a notion and there is no instruction to apply it. Another objective, regarding this scope, in educating National Language is the quality of communicating ideas in speech and written texts as well as the state of contemplating, questioning, and reasoning diverse issues. They learn to ruminate properly and utter and write more rationally and even more reasonably. Therefore, in Iran National Language Curriculum, the critical aspect receives a slight portion without any theoretical and practical instructions.

In Iran Curriculum Framework, while the language arts are mainly taught in psyche-dynamic scope, and students learn to employ language arts in social ties, no activity spotted for them to apply the rules in practice. For example, they attend no collective activity. The students would not experience 
different contexts and occasions and communication is significant in this curriculum but no attempt is done to fulfill the demand.

Besides, students must learn spelling, grammatical, and writing rules and how to use them, so they learn to decode and then decode different texts. They can utilize these skills in producing texts if the methodology of teaching is applicable. The students are instructed in restating old texts concerning modern literary structures and Standard Persian, as well as, they learn to discern the usage of these words and structures in various contexts. They must notice that the literacy and knowledge differ in variant cultures and contexts; thus, the words and structures should agree with the context. Still, any related exercises do not exist.

Another matter to be regarded in our National Language Curriculum, there may be instructions to introduce genres, so the students may learn to distinguish and restate them in Standard Persian. Instructions in recognizing, studying, and evaluating students suggest teaching writing is critically propounded. As students apply their own knowledge in producing texts and creating masterpieces, it is necessary to figure on knowledge efficiency. In this circumstance, education will be an output based theme that's why it underlines the education outcome which is the ability to write a new masterpiece.

The students might learn to use their argumentation potency to study and assess various subjects and create new masterpieces. They may be qualified to contrast different contexts and texts and find negative and positive points in them. Obviously, there is no plan, yet, the students are unknown to master this ability. Namely, they receive no instruction to summarize texts, write episodes and memoirs. Also, they are not taught to review, evaluate matters to choose best words, sentences, and correct punctuation as well as to organize paragraphs. The current curriculum does not arouse the students' curiosities and imaginations, so the students are not educated to process information leading to respond.

The last point to reflect in psyche-dynamic scope will be teaching various dialects simultaneously. Using the dialect consistent with the context plot is a component of educating critical literacy. To instruct Iranian students to use various sources (teaching method of researching) can be somewhat a way of teaching critical literacy.

Respecting the issues drawn from analyzing the foregoing scopes and the table on components of Autonomous and Ideological approaches to literacy, it can be concluded that National Language Curriculum in High Schools is on the boundary between both Autonomous and Ideological approaches to literacy; i.e. the curriculum possesses the characteristics of Autonomous approach to literacy, principally; although it contains some properties of Ideological approaches to literacy in certain instances. It can be expected to include more properties of the latter approach in the National Language Curriculum.

Table 2. The objectives and components of educating writing in National Language Curriculum in High Schools in Iran and U.S.A

\begin{tabular}{|l|l|l|l|}
\hline country & skill & \multicolumn{1}{|c|}{ components } & \multicolumn{1}{c|}{ objectives } \\
\hline U.S.A & Writing & $\begin{array}{l}\text {-Writing as a process } \\
\text {-Writing as a product } \\
\text {-Technique of writing, } \\
\text { dictation, } \\
\text { handwriting } \\
\text {-forms of writing, } \\
\text { audience, and targets }\end{array}$ & $\begin{array}{l}\text {-familiarizing with the pre-writing process, drafting, reviewing, } \\
\text { editing, post-writing process } \\
\text {-writing leading to publishing } \\
\text {-achieving the ability to apply Standard English grammar and writing } \\
\text { legibly } \\
\text {-employing the most impressive structures in writing and mastering all } \\
\text { genres of texts }\end{array}$ \\
\hline Iran & writing & $\begin{array}{l}\text { Diagnosing and applying language arts in communication, } \\
\text { distinguishing genres of writing and improving skill in rewriting them } \\
\text { into Standard Persian, distinguishing and employing spelling and } \\
\text { grammar rules(old and modern) in various texts, utilizing reasoning, } \\
\text { thinking, comparison and creativity and analogy potencies to generate } \\
\text { lingual and literal texts, using Standard Persian along with mother } \\
\text { tongue, using sources properly, rewriting and rendering old literal } \\
\text { works into modern Standard Persian }\end{array}$ \\
\hline
\end{tabular}




\section{Similarities and Dissimilarities between Language Learning Curriculums in the involved countries}

\section{Dissimilarities:}

The Ideological approach to literacy underlines the formularization of National Language Curriculum in the USA while the curriculum is on the boundary between Ideological and Autonomous approaches with Autonomous orientation in educating writing.

- The prospects and purviews are not specified in Iran Curriculums, though; the objectives in writing skill are scrutinized in American Curriculum.

- Education Systems are intensive and decentralized in Iran and USA respectively.

- Educating writing is a critical fashion, though it expects students to achieve this literacy without any education

- Utilizing the Technology Literacy is emphasized in America.

- Activities and educational resources are more varied in American Curriculum than an Iranian one.

- Language Arts are divided into their components while in Iranian one these components are observed inside the education contents.

- Language Learning Curriculum is expounded from Kindergarten to $12^{\text {th }}$ grade in the USA, but education is discussed in three courses: elementary, secondary, high school in Iran.

- Contrary to USA curriculum, there is no association between partial and total targets in Iran.

Similarities:

- Developing a positive attitude toward National Language

- Considering the constructive function of language in fostering reflection and communication

- Applying syncretistic method in Education

- Educating writing critically

- Considering the constructive function of language contexts and plots in curriculums, almost it receives a slight emphasis in Iran.

\section{CONCLUSIONS}

As mentioned, various definitions in two different frames are estimable. Ideological literacy is impressed by cultural-social dimensions, better to say, by ideals, values, and goals, so the society orientate and affect the literacy. The proponents of this model are sensitive to literacy context. They argue the literacy content differs in various contexts. Types of literacy leave different outcomes in various circumstances. In this approach, we apply literacy in referring to a set of capacities beyond the merely reading and writing. It includes multimedia literacy (written, electronic, and speech) as well as all forms of coding and decoding data to convey messages. New Jersey National Language Curriculum signalizes the "Ideological" approach to literacy; hence, educating writing skill is of critical nature and critical literacy is one of the components of Ideological approach to literacy.

In Autonomous approach framework, literacy is separately defined respecting isolated skills and is disconnected from contexts. It lacks critical dimension and it might be mostly treated as a character origin activity. Iran National Language Curriculum is a sample of Autonomous approach to literacy and possesses most components of this approach. Educated people are simply qualified in decoding and recoding the printed works and writing skill is not an exception. In future works an author can study on the following subjects:

- Codification of a decentralized curriculum for teaching all language arts;

- Codification of a coherent curriculum for elementary and high schools;

- Categorizing language arts into their elements; 
- Codification of the guideline on Iran National Language Curriculum once more and eliminating the drawbacks;

- Codification of a National Language Learning curriculum to parallel objectives, methodology, and educational outcomes;

- Emphasizing on using IT, computers, and technology by teachers and students;

- Diversifying the educational materials and activities, as well as flexibility in using them;

- Enhancing information interchange with other countries to recognize the recent achievements and issues;

- Revising or formularizing the National Language Learning curriculum to synchronize Practical and Ideological Education.

\section{References}

[1] Agnello, M.F., A postmodern literacy policy analysis, Peter Lang Pub Inc, New York, 2001.

[2] H. Beder, Adult literacy: Issues for policy and practice, Krieger Pub Co., Malabar, India, 1991.

[3] H. Beder, Adult literacy: Issues for policy and practice, Krieger Pub Co., Malabar, India, 1991.

[4] B. Bloome, M. Englehart, E. Frust, W. Hill, D. Krathwohl, Taxonomy of educational objectives: the classification of educational goals, Handbook 1, cognitive domain, Longmans, Green: New York, Toronto, 1956.

[5] Tousi Maryam Danaye, Ali Reza Kiamanesh, The theoretical approaches to literacy: evidence from America, Canada, England, Singapore, Senegal, Indonesia and Iran's curriculum, Iranian Journal of Educational Innovations, 31:8 (2009) 31-46.

[6] Leili Dastoori, Comparative study of teaching creative writing (composition) in national curriculum of Iran, America \& England at primary stage, M.S. thesis, Dept. Linguistic and Languages, Univ. Payame Nour university, Tehran, Iran, 2009.

[7] P. Drucker, The age of social transformation [Electronic version], Atlantic Monthly, 1994, pp.53-79.

[8] Marlo Ediger, Writing, The pupil and the social studies, College student journal, 34:1 (2000).

[9] J. Flood, J.M. Jensen, Handbook of research on teaching the language arts, Free Press, 1991.

[10] Moghadam Hossein Ghasempour, Bahman Zandi, Maryam Bakhshesh, A comparative study on national language programs at elementary level in Iran and US, Journal of curriculum studies. 3:8 (2008) 1-22.

[11] Moghadam Hossein Ghasempour, The study of philosophic, psychological and linguistic principles of Persian curriculum in elementary level, Journal of curriculum studies. 3:10, (2008) 18-41.

[12] R.M. Hammett, B.R. Barrell, Media literacy and English language arts, Ricci Nipissing Univ., Carlo, Canada, 2002.

[13] Vantassel-Baska Joyce, A curriculum study of gifted-students learning in the language arts, Gifted child quarterly. 46:1 (2002) 30-44.

[14] Mir Javad Kermani, Survey contents of Persian books $(1,2)$ of the first course in High Schools based on planning and psychological doctrines from teachers' and students' standpoints in the first course of high school in Tabriz, M.S. thesis, Dept. Education, Univ. Kharazmi, Tehran, Iran, 1998. 
[15] A.J. Liddicoat (ed.), Language planning and Policy: Issues in language planning and literacy, Multilingual Matters, Clevedon, United Kingdom, 2007, pp. 13-29.

[16] L. Malkin, C.J. Diaz, C. Mclanchlar, Literacy's in early childhood, changing views, challenging practice, $2^{\text {nd }}$ ed., Marrickvill, Australia, 2002, pp. 257-271.

[17] Nader Salsabili, Presenting a guide schema in applying policies in planning curriculum systems in modern high school course, $\mathrm{PhD}$ dissertation, Dept. Education and lesson planning, Univ. Kharazmi, Tehran, Iran, 2000.

[18] Manijeh Sepehri, National curriculum in primary education, M.S. thesis, Dept. Education, Univ. Sheffield, London, England, 1996.

[19] Sandra Stotsky, An English language arts curriculum framework for American public schools, University of Arkansas, USA, Feb. 2013.

[20] B. Street, Social literacy: critical approaches to literacy in development, Education and Ethnography, Longman, London, United Kingdom, 1995.

[21] B. Street, Literacy and development: Ethnographic Perspectives, Rout ledge, London, United Kingdom, 2001.

[22] B. Street, Cross-cultural approaches to literacy, Cambridge University press, Cambridge, United Kingdom, 1993, pp. 1-21. 